\title{
Um mosaico dos trabalhos publicados nos anais do SIPEM: foco nos livros didáticos e nos materiais cur- riculares
}

\author{
Ana Paula Perovano \\ Universidade Estadual Paulista, Rio \\ Claro

פapperovano@uesb.edu.br
Douglas Ribeiro
Guimarães (i)
Universidade Estadual Paulista, Rio
Claro
$\square$ douglasrguimaraes@hotmail.com

\section{A mosaic of works published in the proceedings of SIPEM: focus on textbooks and curricular materials}

\begin{abstract}
Textbooks play an important role in the teaching and learning of mathematics, as they are considered as translators of the curriculum of a country, showing the political, economic, cultural and knowledge patterns of a society. Therefore, we considers relevant, a careful look at this resource. This text is the result of a study that aimed to identify which thematic focuses about textbooks have emerged in the works published in the proceedings of the International Research Seminar in Mathematics Education. For this purpose, we carried out an investigation with a qualitative approach, in which we used documentary analysis in the proceedings of that event. We mapped and described the publications and, as a result, we identified that there is a marked presence of research aimed at analyzing the textbook, as there is a lack of research that deals with its use and how textbooks are produced.
\end{abstract}

Key words: Mapping; Textbook; Curricular Material; Mathematics Education.

\section{Resumo}

Os livros didáticos desempenham um papel importante no ensino e na aprendizagem de Matemática, pois são considerados como tradutores do currículo de um país, evidenciando os padrões políticos, econômicos, culturais e de conhecimento de uma sociedade. Assim, estimamos como relevante um olhar criterioso para esse recurso. Este texto é o resultado de um estudo que teve como objetivo identificar quais focos temáticos sobre livros didáticos têm emergido nos trabalhos publicados nos anais das três últimas edições do Seminário Internacional de Pesquisa em Educação Matemática. Para tanto, realizamos uma investigação com abordagem qualitativa, em que empregamos a análise documental nos anais do referido evento. Mapeamos e descrevemos as publicações e, como resultado, identificamos que é marcante a presença de pesquisas destinadas à análise do livro didático e há carência de pesquisas que tratem do seu uso e de como os livros didáticos são produzidos.

Palavras-chave: Mapeamento; Livro Didático; Material Curricular; Educação Matemática. 


\section{INTRODUÇÃO}

O livro didático é o objeto de pesquisa dos dois autores, a ser analisado pela lente da Educação Matemática Crítica e na discussão sobre avaliação e escolha desse recurso pelos professores. Pontuamos que, em nossos estudos, identificamos uma variedade de pesquisas que tentam captar as nuances inerentes ao livro didático.

$\mathrm{Na}$ intenção de compreender a produção de conhecimento brasileira sobre esse objeto, iniciamos uma busca nos anais de eventos nacionais e internacionais e, para este texto, nosso foco serão os anais das três últimas edições do Seminário Internacional de Pesquisa em Educação Matemática (SIPEM). Trata-se de um evento idealizado pela Sociedade Brasileira de Educação Matemática (SBEM), com a finalidade de promover o intercâmbio entre os pesquisadores da área da Educação Matemática, embora não haja um Grupo de Trabalho específico para tratar das pesquisas sobre o livro didático. Um dos recursos utilizados pelos professores em sua atuação docente é o livro didático, que se constitui como um ponto de referência para o planejamento e para a realização de suas aulas ou avaliações; assim, "ele pode ser decisivo para a qualidade do aprendizado resultante das atividades escolares" [1] (p. 23)

A importância do livro didático na educação brasileira deve-se à sua colaboração "na divulgação dos saberes socialmente legitimados das diferentes áreas de conhecimento, na organização da atividade docente, nos interesses econômicos envolvidos em sua produção e comercialização e nos investimentos do Estado" [2] (p. 258). Ou seja, ele é uma engrenagem no sistema educacional e, portanto, é relevante pesquisálo como tal.

\section{LIVRO DIDÁTICO}

Ao empregar pesquisas que tomam o livro didático como objeto de estudo, concordamos com [3], que justifica essa opção porque o objetivo principal delas é, de alguma forma, melhorar o ensino e a aprendizagem (de Matemática). Sendo assim, quando decidimos realizar o mapeamento de algumas dessas pesquisas, com foco nos anais de um evento importante da Educação Matemática brasileira, esse objetivo permeou nossos caminhos.

O campo de pesquisa sobre livros didáticos pode ser ampliado ao trazer implicações desse objeto com outros fatores, evidenciando as formulações dos referenciais teóricos e metodológicos, além de oportunizar maiores avanços com relação às pesquisas empíricas e experimentais [3]. Apesar desse esforço, ainda temos pesquisas que analisam o livro didático em si, identificando, por exemplo, abordagens do seu conteúdo. Consideramos que essas pesquisas são fundamentais, mas precisamos ampliar os olhares para outras implicações, como as políticas públicas (no caso do 
Brasil) que produzem e distribuem os livros didáticos, os processos de escolha desses recursos, bem como o seu uso pelos alunos e professores em sala de aula.

Queremos deixar claro que tomar esse recurso como objeto de estudo não exclui a possibilidade de outros, como bem mostrado por [4] e [5], em que o professor tem mais liberdade de escolha para a sua prática docente, integrando e complementando o livro com outros recursos. Usamos o termo recurso, por ele possibilitar a ideia de uma "ampla variedade de tipos possíveis de ferramentas, incluindo materiais instrucionais impressos ou digitais, simulações, vídeos, ferramentas interativas, e similares" [6] (p. 88).

Não poderíamos deixar de mencionar, também, a importância do Programa Nacional do Livro e do Material Didático (PNLD), que propicia discussões, principalmente pelo caráter de seleção, avaliação e distribuição de livros para as escolas públicas de todo o país, programa esse que movimenta bilhões de reais todos os anos, conforme dados $^{1}$ do Fundo Nacional de Desenvolvimento da Educação (FNDE). No PNLD, são lançados editais para que os autores, junto às editoras, submetam suas propostas e depois de um processo avaliativo, que envolve especialistas de cada área, são elaboradas resenhas de cada coleção aprovada para, então, compor o Guia de Livros Didáticos. Esse Guia pode ser acessado pelos professores e os demais envolvidos das escolas, para respaldar as escolhas dos professores de cada disciplina.

Outro recurso que vem ganhando atenção há algum tempo, refere-se aos materiais curriculares, principalmente quando relacionados ao uso pelo professor e sua consequente relação professor-materiais curriculares, como mostram [7] e [8]. Esses materiais não se limitam aos livros didáticos, eles podem ser impressos ou digitais, por exemplo, guias para os professores, apostilas, livro do aluno, entre outros. Mais recentemente, como explica [6], o termo "recursos curriculares" aparece na literatura e, assim, podem ser incluídos artefatos, impressos ou digitais, que apoiam um programa de instrução e aprendizado dos estudantes.

Desse modo, entendemos que os livros didáticos podem ser tomados como objeto de estudo para as pesquisas em Educação Matemática, principalmente por serem considerados recursos importantes para o trabalho em sala de aula. Assumimos, também, que os estudos sobre materiais ou recursos curriculares são necessários, uma vez que podem revelar as práticas usadas nos processos de ensino e aprendizagem.

A seguir, explicamos a metodologia empregada na pesquisa e apresentamos os dados produzidos, oriundos dos anais de três edições do Seminário Internacional de Pesquisa em Educação Matemática.

\footnotetext{
${ }^{1}$ Disponível em: https://www.fnde.gov.br/index.php/programas/programas-do-livro/pnld/ dados-estatisticos. (acesso em 5 setembro 2020).
} 


\section{METODOLOGIA}

Uma conceituação para a metodologia de pesquisa é apresentada por [9], entendida como um caminho do pensamento e sua prática exercida ao abordar a realidade. Inclui-se, nessa perspectiva, a abordagem adotada (os métodos), os instrumentos de operação do conhecimento (as técnicas) e a criatividade do pesquisador, ou seja, sua experiência, sensibilidade e sua capacidade pessoal.

Isso posto, assumimos que a abordagem empregada neste estudo é qualitativa, pois filtramos os dados através de uma lente pessoal posicionada em um momento sociopolítico e histórico [10] (p. 186). Nesse tipo de abordagem, o desenho da pesquisa é aberto, flexível, elaborado durante a realização do estudo [11].

Utilizamos a análise documental com a intenção de observar, nos documentos, informações a respeito das pesquisas sobre livro didático de Matemática. Neste estudo, estamos considerando como documentos os anais do Seminário Internacional de Pesquisa em Educação Matemática (SIPEM), pois, conforme afirma [12], entre os tipos de documentos que são considerados na análise documental destacam-se leis, regulamentos, normas, pareceres, memorandos, diários pessoais, autobiografias, jornais, revistas, livros e arquivos escolares, entre outros. [13] também corrobora essa visão, pois considera que qualquer registro escrito é um documento e, sendo assim, pode ser usado como fonte de informação.

Escolhemos os anais do SIPEM por ser um evento realizado no Brasil que, a exemplo de outros como o Psychology Mathematics Education (PME) e o International Congress on Mathematical Education (ICME), oferece um espaço para que os pesquisadores possam discutir temáticas da Educação Matemática de forma mais aprofundada. É um evento promovido pela Sociedade Brasileira de Educação Matemática (SBEM) cujos objetivos são:

- Promover o intercâmbio entre os grupos que, em diferentes países, se dedicam às pesquisas, cujo tema é a Educação Matemática;

- Divulgar as pesquisas brasileiras no âmbito da Educação Matemática;

- Promover o encontro dos pesquisadores em Educação Matemática, proporcionando-Ihes a possibilidade de conhecer as investigações que estão sendo realizadas na atualidade;

- Propiciar a formação de grupos integrados de pesquisas que congreguem pesquisadores brasileiros e estrangeiros;

- Possibilitar o avanço das pesquisas em Educação Matemática [14]. 
O SIPEM possui periodicidade trienal e teve seu início em 2000. No ano de 2018, ocorreu a sétima edição do evento na cidade de Foz do Iguaçu e, a cada edição, são publicados os anais que constituem os registros do conhecimento produzido pelo evento.

Inicialmente lemos os anais das sete edições do evento e selecionamos os textos que abordavam o tema livro didático, seja no título e/ou em seu resumo; agregamos, também, aqueles que abordavam os materiais curriculares e encontramos 43 textos no total. Efetuamos a leitura de todos os resumos, porém, neste artigo, discutiremos 19 trabalhos publicados a partir de 2012, ou seja, os trabalhos publicados nas três últimas edições do SIPEM. Optamos por essa delimitação, porque os anais das primeiras edições do evento não possuem um padrão; alguns trabalhos publicaram um resumo e outros um resumo estendido, mas, a partir de 2012, os anais passaram a conter os trabalhos completos, sendo essa a justificativa de nossa opção.

Metodologicamente, utilizamos o que é nomeado por [15] como mapeamento da pesquisa. Para os referidos autores, trata-se de "[...] um processo sistemático de levantamento e descrição de informações acerca das pesquisas produzidas sobre um campo específico de estudo, abrangendo um determinado espaço (lugar) e período de tempo. Essas informações dizem respeito aos aspectos físicos dessa produção (descrevendo onde, quando e quantos estudos foram produzidos ao longo do período e quem foram os autores e participantes dessa produção), bem como aos seus aspectos teórico-metodológicos e temáticos" [15] (p. 18).

A apresentação da análise dos dados foi agrupada em categorias que se projetaram de nossos momentos de reflexões. Empregamos a categorização porque, na perspectiva de [16], trabalhar com categorias significa agrupar elementos, ideias ou expressões em torno de um conceito capaz de abranger os significados. Corroborando essa visão, [17] entendem a categorização como um processo de seleção ou de organização de informações em categorias estabelecidas, ou seja, em classes ou conjuntos que contenham elementos ou características comuns.

Cabe mencionar que, para a validação da categorização, cada autor efetuou uma categorização individual prévia, a partir da leitura dos títulos e resumos dos 19 textos. Tal categorização foi, então, confrontada e, posteriormente, validada com a leitura integral de todos os trabalhos publicados nos anais do SIPEM. Neste processo, elaboramos quatro categorias: Análise do Conteúdo; Análise Comparativa; Materiais Curriculares; e Outros. A Tabela 1 apresenta a distribuição dos textos nas categorias encontradas.

Prosseguiremos na próxima seção com a apresentação e discussão das categorias indicadas na Tabela 1 . 
Tabela 1. Distribuição dos textos por categorias e ano.

\begin{tabular}{|l|c|c|c|c|}
\hline $\begin{array}{c}\text { Ano do Evento } \\
\text { Edição }\end{array}$ & $\begin{array}{c}2012 \\
\text { V SIPEM }\end{array}$ & $\begin{array}{c}2015 \\
\text { VI SIPEM }\end{array}$ & $\begin{array}{c}2018 \\
\text { VII SIPEM }\end{array}$ & Total \\
\hline Análise do Conteúdo & - & 2 & 4 & $\mathbf{6}$ \\
\hline Análise Comparativa & 3 & - & 1 & $\mathbf{4}$ \\
\hline Materiais Curriculares & 1 & 2 & 1 & $\mathbf{4}$ \\
\hline Outros & 2 & 2 & 1 & $\mathbf{5}$ \\
\hline Total & $\mathbf{6}$ & $\mathbf{6}$ & $\mathbf{7}$ & $\mathbf{1 9}$ \\
\hline
\end{tabular}

Fonte: Elaborada pelos autores.

\section{UM OLHAR PARA OS DADOS}

Esta seção tem por objetivo apresentar e descrever as categorias que se delinearam durante o mapeamento. Salientamos que, inicialmente, tínhamos ideia de que surgiriam categorias como as apresentadas por [18]: Comparação; Análise do livro; Uso do livro e outras áreas (livros eletrônicos, relação entre livros e estudantes). No entanto, não identificamos as três últimas categorias e, como explicado anteriormente, elaboramos outras, quais sejam: análise do conteúdo, materiais curriculares e outros (políticas públicas, revisão de literatura e a análise de gênero). Passaremos a explicar nosso entendimento sobre as categorias e descrevê-las a seguir.

\subsection{Análise do Conteúdo}

Essa categoria foi destinada para os trabalhos que analisaram um conteúdo matemático específico ou um bloco de conteúdos, ou até mesmo um tema, num único livro ou numa coleção de livros didáticos. Dessa forma, os trabalhos elencam como um conteúdo ou um tema é referido nos livros didáticos, desde os Anos Iniciais do Ensino Fundamental [19] até o Ensino Superior [20].

Buscando estabelecer características de exercícios de livros didáticos de Matemática Financeira do Ensino Superior que sinalizam possíveis fronteiras com situações do cotidiano e de ambientes de trabalho [20] empregaram o conceito de prática proposto por [21], pois os exercícios apresentados nos livros são reificações de práticas distintas que apresentam características comuns que se conectam com a Matemática Financeira disciplinar. Identificaram que os todos os exercícios analisados foram baseados em situações semirreais, que são situações inventadas, baseadas nas situações reais [22] e admitiam apenas uma resposta correta. Finalizam, evidenciando que os exercícios que envolvem processo de tomada de decisão, os quais permitem uma aproximação com experiências que se assemelham com situações do cotidiano e de ambientes de trabalho, não são devidamente explorados.

Matemática Financeira foi o conteúdo analisado também por [23], com a intenção de evidenciar as positividades desse conteúdo em outros momentos da História. Em- 
pregaram a Arquegenealogia de [24] e examinaram os livros, "Matemática 2a série" de Osvaldo Sangiorgi, da década de 1960, e "Matemática e Estatística para os Institutos de Educação e Escolas Normais", do mesmo autor, datado de 1956. Para integrar as reflexões no contexto da educação escolar atual, empregaram o livro "Matemática: contexto e aplicações" de Luiz Roberto Dante, de 2016.

Em suas análises, as autoras revelaram que, mesmo nos anos iniciais, os livros didáticos de Matemática de meados da década de 50 e 60 abordavam o sistema monetário, apresentando problemas que envolvem as quatro operações em situações de preço e consumo; em livros destinados à formação de professores, abordavam problemas, relacionados ao rendimento da poupança ou ao consumo de produtos financeiros, tais como empréstimos. Atualmente, os livros apresentam outra abordagem, dando destaque para tomada de decisão, buscando o controle do consumo pessoal, devendo cada sujeito responsabilizar-se, como bons consumidores para promover a manutenção e estabilidade de uma ordem social econômica.

Ao analisar abordagem dada às funções composta e inversa, presentes em três coleções de livros didáticos do Ensino Médio, aprovados pelo PNLD de 2015 e, especialmente, [25] investigaram os tipos de registros de representações semióticas [26], envolvidos nos exercícios propostos e resolvidos. Os autores constataram três abordagens: i) uma não trata de função composta e utiliza apenas um método algébrico para determinar uma função inversa; ii) outra trata de ambos os tipos de função, porém não as relacionam e, iii) e a terceira trata da relação entre funções composta e inversa, sem, entretanto, definir previamente função composta, o que pode comprometer o entendimento desses conceitos pelo aluno.

Foi evidenciado pelos autores que os livros didáticos avaliados priorizavam o registro algébrico em detrimento do registro gráfico e privilegiavam transformações de tratamento, o que, de certa forma, pode comprometer a apreensão, pelos alunos, desses objetos matemáticos.

Com o objetivo de analisar o modo como dois livros didáticos do $7^{\circ}$ ano do Ensino Fundamental apresentam o conceito de números inteiros, a partir da Teoria dos Campos Conceituais e obstáculos epistemológicos [27] identificaram que os livros analisados apresentam uma diversidade de situações para representar altitudes, finanças e fuso horário, situações que possibilitam, segundo as lentes teóricas, a oportunidade de enfrentamento da aceitação do número negativo, ampliando o significado atrelado ao conceito. Em relação às operações de adição e subtração, inicialmente são apresentadas várias situações; no entanto, os livros acabam voltando-se a fórmulas e procedimentos. Sobre as operações de divisão e multiplicação não foram evidenciadas situações que dessem sentido a esses conceitos; a atenção, nessas operações referese à apresentação de procedimentos para que o aluno execute os cálculos. 
Utilizando o Enfoque Ontossemiótico de [28], [29] analisaram os conteúdos de Geometria de um livro didático do $5^{\circ}$ ano. Os autores identificaram que a formalização dos conceitos em linguagem adequada, apreensão com as aplicações e questões interdisciplinares, com o incentivo à utilização de materiais concretos em atividades diversas e jogos. Destacaram ser possível utilizar os quadros de adequação didática do Enfoque Ontossemiótico para a análise de materiais curriculares, visto que os quadros permitem a apreciação de diversas categorias que podem auxiliar docentes na avaliação desses materiais.

Em vista da importância do sistema de numeração decimal, [30] analisou cinco coleções de livros didáticos destinados aos Anos Iniciais do Ensino Fundamental, analisando as indicações de uso de Blocos Base Dez (BBD). O autor problematiza casos de indicações ao uso de BBD para o ensino e a aprendizagem do sistema de numeração Indo-Arábico e operações aritméticas. Identificou que todos eles apresentam os BBD de forma "solta" e, embora estejam organizados por ordem de grandeza, não estão inseridos em nenhum tipo de tabela ou quadro. Apesar de o material já estar estruturado em agrupamento de 10, o número de unidades correspondente a cada bloco é relembrado repetidas vezes. E quando o $\mathrm{BBD}$ é trabalhado junto com o Quadro de Valor Lugar (QVL), ao inserir, por exemplo, um bloco que vale 100 unidades (placa) na ordem das centenas em um QVL, pode gerar confusões por parte da criança. Para o autor, a escolha do material correto e a clara e participativa instrução do professor garantirão a efetiva aprendizagem de conceitos de Matemática por parte do aluno.

Apesar de estar em um mesmo grupo, os trabalhos que analisaram um conteúdo ou um bloco de conteúdos, não possuem um mesmo referencial teórico e como resultados evidenciam: a mudança de abordagem constituída historicamente para os conteúdos de Matemática Financeira [23], a possibilidade de utilização dos quadros de adequação didática para avaliação de livros didáticos e algumas necessidades, como a devida exploração dos exercícios que envolvem o processo de tomada de decisão em Matemática Financeira [20], situações que deem sentido às operações de multiplicação e divisão ao abordar os números inteiros [27] e não privilegiar o registro algébrico ao abordar função composta e inversa [25], bem como o cuidado ao abordar a utilização do BBD com o QVL [30].

\subsection{Análise Comparativa}

A análise comparativa decorre das investigações que se ocupam em compreender as semelhanças e diferenças de, pelo menos, dois livros didáticos. Os dados que trazemos indicam uma versatilidade em, por exemplo, ano de escolaridade a que se destinam os livros, análise comparativa entre países e análise histórica de coleções em um mesmo país. Além disso, as fundamentações teóricas e os procedimentos 
metodológicos diferem, apontando para ricas discussões nessa temática da análise comparativa.

Com o objetivo de analisar dois livros didáticos de Matemática de 1943 e de 1966 e verificar suas relações com os dois movimentos modernizadores do ensino secundário dessa matéria [31] apresentam as principais características de cada um dos movimentos, com o objetivo de situar a análise das obras, para depois compará-las. Mostram as estruturas dos livros, como características físicas, sequenciamento dos conteúdos, e as representações como as figuras geométricas. Os resultados mostraram que a obra de 1943 não estava em conformidade com ideais do Primeiro Movimento, diferentemente do livro de 1966, que cumpriu seu papel, em consonância com o Segundo Movimento.

Na pesquisa de [32], é feita uma análise comparativa de seis livros didáticos, brasileiros e espanhóis, pertencentes aos três primeiros anos do Ensino Fundamental. $O$ foco está nas atividades sobre o Sistema de Numeração Decimal. A autora propõe como método analítico a divisão em variáveis como finalidade, função dos números, material e representação. As discussões das atividades, que somaram 7.026, mesclam dados quantitativos, mostrados em gráficos, mas fazem também uma análise qualitativa, em que descrevem e refletem sobre eles. De modo geral, os livros brasileiros utilizam mais os desenhos, sejam eles para ilustrar ou ensinar o conteúdo, enquanto os livros espanhóis dão destaque para os cálculos repetitivos e sem contextos. Para [32], ensinar a lógica do sistema de numeração deve ter como objetivo a mesma lógica de ensinar o sistema alfabético, propondo discussões e reflexões para os estudantes.

Comparar livros didáticos do $7^{\circ}$ ano do Ensino Fundamental com o tema de Equações do $1^{\circ}$ grau é o objetivo da pesquisa de [33]. Apesar de não explicitarem, entendemos que a análise comparou tanto as obras dos mesmos autores, por realizarem um estudo com livros de 1999 e 2011, quanto comparam as obras de autores diferentes. Utilizando o aporte da Teoria Antropológica do Didático (TAD), explicam as organizações matemáticas e didáticas. Mostram ainda, a evolução histórica da Álgebra; como o currículo apresenta essa área; e, além disso, os elementos que constituem uma Equação do $1^{\circ} \mathrm{grau}$. A metodologia foi dividida em duas etapas, primeiro considerando uma modelização a priori, identificando as tarefas, técnicas e tecnologias dos conteúdos, e a segunda com a análise das obras, apresentando a estrutura e forma de organização dos conteúdos. Os autores concluem que as obras não mudaram as praxeologias matemáticas, mas modificaram as praxeologias didáticas; ademais, em comparação com 1999, os livros de 2011 incluem mais problemas relacionados às equações do que apenas exercícios mais diretos para resolução.

Uma análise comparativa do currículo e dos livros didáticos brasileiros e suecos foi realizada por [34]. Partem das noções de cidadão matematicamente competente e 
da governamentalidade ao investigar os documentos e livros destinados ao $9^{\circ}$ ano do Ensino Fundamental. Os resultados mostram que os materiais suecos privilegiam o tema de programação, além de regularem o sistema de avaliação e, além disso, é nos documentos curriculares que se encontram as noções de competência matemática. No caso do Brasil, os livros desempenham esse papel da competência, principalmente ao deixar em evidência normas e valores de "boa conduta". Nos livros suecos, as atividades focam nos esportes e atividades da natureza, enquanto no Brasil o foco está na discussão sobre preservação de recursos naturais. Por fim, os autores entendem que deve ser realizado um trabalho do impacto da Base Nacional Comum Curricular nos livros brasileiros.

Entendemos que as pesquisas que propõem comparações entre livros didáticos revelam variadas inquietações de seus autores. Por exemplo, [31] mostram uma concepção de livro como documento, ou seja, quais discussões podem ser empregadas a partir desse recurso e de que forma as manifestações históricas estão presentes nesse documento. Já [32] e [33], apresentam aspectos metodológicos relevantes para a análise de livros, uma vez que têm a preocupação com determinados conteúdos. Por sua vez, [34], por não se preocuparem com um conteúdo específico, mas considerando a etapa escolar, ressaltam a forma com que os livros e também o currículo manifestam suas posições com relação às características culturais e políticas, evidenciando qual a formação desejável para os estudantes.

\subsection{Materiais Curriculares}

Consideramos relevante evidenciar que, em nosso levantamento, trabalhos que abordavam os materiais curriculares aparecem a partir de 2012 e continuam nas outras edições, de 2015 e 2018. Destacamos a existência de uma variação na nomenclatura empregada para denominar os objetos utilizados pelos professores e alunos no processo de ensino e aprendizagem: recurso didático, materiais didáticos, materiais pedagógicos, recursos pedagógicos, meios auxiliares de ensino e materiais curriculares, entre outros. Aqui, os materiais curriculares podem ser entendidos como propostas elaboradas pelas Secretarias Estaduais e Municipais, com o intuito de implementar inovações no ensino.

Uma análise documental em uma abordagem qualitativa em que analisaram o texto dos materiais curriculares educativos sobre modelagem matemática, no que se refere a um discurso de ordem, cujo objetivo é a organização social do contexto (discurso regulativo) foi realizada por [35]. As autoras fundamentam-se em [36] que atribuem o adjetivo educativo ao material curricular que é elaborado com o propósito de promover a aprendizagem dos alunos e dos professores. Empregaram as ideias de [37], a respeito do discurso pedagógico que é "um princípio para apropriar outros discursos 
e colocá-los numa relação mútua especial, com vistas à sua transmissão e aquisição seletivas" (p. 183). As autoras concluem que, ao deixar claras as regras do discurso contido nos materiais, ficam visíveis as intenções pedagógicas dos elaboradores e, dessa forma, os professores terão informações que possibilitam a escolha dos materiais e contextos pedagógicos, cujas modificações e/ou adaptações não diluam os princípios do discurso regulativo, indicados pelos elaboradores.

O objetivo da pesquisa de [38] foi compreender como duas professoras polivalentes interpretam e utilizam materiais curriculares sobre o tema Espaço e Forma em suas aulas. Pautadas nos estudos de [39], as autoras identificaram que as atividades propostas pelo material, apresentam orientações objetivas para cada atividade, proporcionam a progressão dos conteúdos pautados nas expectativas de aprendizagem e revelam a concepção teórica adotada. As autoras constataram que adaptações, criações e reproduções do material, em uma única aula, carregam recursos do professor (conhecimentos do assunto, pedagógicos e crenças) o que pode não contemplar os objetivos previstos para aquela atividade/conteúdo. Para obter bons resultados, na visão de [38], é preciso formação constante por parte dos professores para ampliarem seus conhecimentos didáticos e matemáticos e, consequentemente, desconstruir crenças. O conhecimento do material curricular que está sendo utilizado é tido como essencial.

Algumas ideias para análise de materiais curriculares, objetivando contribuir para o debate sobre currículos de Matemática e sobre políticas públicas que envolvem avaliação e distribuição desses materiais foram apresentadas por [40]. Pautada nas ideias de [41], [42] e [43], a autora apresenta um quadro de análise para materiais curriculares e materiais curriculares educativos que, na visão da autora, podem contribuir para as reflexões e análises de materiais curriculares, sejam eles livros didáticos ou cadernos produzidos por Secretarias de Educação.

Aspectos dos materiais curriculares que podem contribuir para a aprendizagem matemática do professor são discutidos por [44]. Os autores apresentaram uma discussão numa perspectiva de estudo teórico de abordagem qualitativa, evidenciando que os materiais curriculares educativos são considerados como agentes de possibilidades para a prática pedagógica, e podem auxiliar os professores no entendimento, na organização e no sequenciamento das situações de aprendizagem, a fim de fornecer elementos para a tomada de decisões sobre como relacionar as unidades de estudo. Na visão dos autores, tais materiais curriculares podem contribuir para o conhecimento matemático para o ensino, por meio de uma análise crítica, sendo possível a relação, e essa análise ser objetos da formação.

Dos quatro trabalhos reunidos nessa categoria, um deles aborda um tema de conteúdos: Espaço e Forma [38] em que as autoras constatam ser essencial, para o pro- 
fessor, conhecer o material curricular que está sendo utilizado. Outro trabalho evidencia a relevância de deixar claras as regras do discurso contido nos materiais curriculares educativos que envolvem a modelagem matemática [35]. Colaborando para o debate sobre currículos, [40] apresenta um quadro de análise para materiais curriculares; [44] evidenciam que tais materiais podem contribuir para a aprendizagem do professor por meio de uma análise crítica.

\subsection{Outros}

Trazemos nesta seção os trabalhos que não se enquadram nas seções anteriores e, também, por não representarem um número elevado de pesquisas para formar uma nova categoria, quando comparados aos seis ou quatro textos que compõem a análises do conteúdo, as análises comparativas e os materiais curriculares. Dessa forma, os textos da categoria "outros" discutem as políticas públicas, com foco histórico ou de escolha do livro, bem como revelam a articulação de livros didáticos com outros elementos curriculares e práticas pedagógicas, mostrando, ainda, uma revisão de literatura e a análise de gênero, no caso, o gênero feminino.

O objetivo do trabalho de [45] é analisar duas obras que orientavam os professores brasileiros para o ensino primário de Matemática. A autora seleciona os manuais escolares do português Faria de Vasconcelos, datados de 1933 e 1934, que tinham o foco em aritmética. A autora traz fundamentos da história cultural em sua análise e explica os impactos das obras do autor para o movimento da Escola Nova. Esclarece que os manuais, difundidos na época, tratam-se de guias ou livros do professor, e mostra as apropriações de Vasconcelos do movimento escolanovista para o ensino da aritmética. Por fim, explica que o autor foi o responsável pelas obras mais citadas entre as décadas de 1940 e 1970, por professores brasileiros.

Na pesquisa de [46], são apresentados os critérios que os professores dos Anos Iniciais do Ensino Fundamental, em uma cidade do Rio de Janeiro, utilizam para escolher os livros didáticos de Matemática. As autoras entrevistaram 82 professores de 11 escolas e, ainda, Coordenadores Pedagógicos, Diretores e uma pessoa responsável pelo PNLD no município. Entre os critérios elencados pelos professores estão: considerar a realidade dos alunos, conhecer qual a abordagem didática dos livros, os conteúdos e as atividades e, ainda, a escolha pela mesma editora do livro de Língua Portuguesa. O Guia dos livros didáticos não foi utilizado como critério de seleção e [46] apontam para a necessária urgência em investimentos na formação desses professores.

Apresentar os resultados de uma pesquisa colaborativa que analisou documentos curriculares, livros didáticos, provas e relatos de professoras com foco no $5^{\circ}$ ano do Ensino Fundamental é o objetivo na pesquisa de [47] que contou com um grupo de 30 participantes. Entre estes, temos professoras da Educação Básica, estudantes 
de graduação e pós-graduação e outros colaboradores. Nesse grupo, a partir das discussões de [48] sobre currículo e de [49] sobre análise didática, foram analisados os temas de Números Naturais, Operações, Relações Espaciais e Figuras Geométricas Espaciais.

A autora mostra que existe uma convergência dos currículos, prescrito, moldado e avaliado quando visto sob a perspectiva do SAEB (Sistema de Avaliação da Educação Básica) e que há divergências entre os currículos prescritos e avaliados quando olhados no sentido das ações das professoras em sala e a utilização do livro didático. Afirma, ainda, que as professoras utilizam em seu planejamento o que aprenderam na Educação Básica e não nos escritos dos documentos curriculares.

As questões de pesquisa em teses e dissertações nas áreas de Ensino e Ensino de Ciências e Matemática, que tinham o livro didático (LD) como objeto de estudo foram mapeadas por [50]. Encontraram um total de 59 trabalhos e seguiram as classificações propostas por [51] e [3], a saber: questões descritivas, correlacionais e causais. Identificaram que $80 \%$ das pesquisas eram do primeiro grupo, ou seja, descrições conceituais, didático-metodológicas, relação professor-currículo e relação aluno-currículo. As questões correlacionais e causais apareceram em $8 \%$ e 12\%, respectivamente. Os autores concluem que para a constituição de um campo de pesquisa sobre livros didáticos e outros materiais, na Educação Matemática, precisamos avançar em questões correlacionais, que veem a influência de outros fatores nos LD, e em questões causais, que analisam como o LD influência outros fatores.

O objetivo da pesquisa de [52] é analisar duas coleções de livros didáticos dos Anos Iniciais do Ensino fundamental, aprovadas pelo PNLD Campo, em 2013 e 2016. Partindo de um processo de problematização, com as discussões de Michel Foucault, a autora apresenta práticas, que constituem o "sujeito-mãe", presentes em atividades, imagens e textos. [52] separou os dados em sete categorias: afeto, segurança, saúde, gestão, justiça, trabalho e comportamento, evidenciando que o currículo de Matemática confirma práticas que regularizam e formam a identidade cultural do "sujeito-mãe".

Destacamos que essa categoria apresenta uma diversificação de pesquisas e possibilita o aprofundamento de outras, por exemplo, [45] realiza uma pesquisa semeIhante à de [31], no entanto, a autora não faz uma análise que compara os livros e sim mostra as influências desses em um período histórico. As preocupações de [46] e [47], quanto à escolha de livros e as relações com os currículos, respectivamente, apontam para investigações futuras, mudando a etapa escolar, por exemplo, que focou nos Anos Iniciais do Ensino Fundamental. Já [50] indicam, claramente, a mudança em relação às pesquisas com livros didáticos, investigando questões correlacionais e causais. Por fim, as discussões de [52] também podem ser ampliadas, com foco em outros editais do PNLD, uma vez que o PNLD Campo não lançou outras chamadas e 
foi cancelado em 2018.

\section{CONSIDERAÇÕES FINAIS}

A partir do mapeamento realizado com os anais de três edições do Seminário Internacional de Pesquisa em Educação Matemática (SIPEM), pode-se perceber que o emprego dessa metodologia auxilia o desenvolvimento de novas pesquisas, em particular para a Educação Matemática. Entendemos que esse trabalho indicou o direcionamento das pesquisas com livros didáticos e, também com os materiais curriculares.

O mapeamento nos deu uma ideia de um mosaico sobre as pesquisas a respeito do livro didático em que cada peça encaixada "contribui um pouco para a nossa compreensão do quadro como um todo. [...] Diferentes fragmentos contribuem diferentemente para nossa compreensão: alguns são úteis por sua cor, outros por que realçam os contornos de um objeto“ [53] (pp. 104-105).

Ao lançar nosso olhar sobre o mosaico produzido a partir do mapeamento, identificamos diferentes referenciais teóricos que foram utilizados, por exemplo: Teorias da Didática Francesa [25, 27, 33], Educação Matemática Crítica [20], Enfoque Ontossemiótico [29] e Reflexões foucaultianas [23, 51]. Ou seja, no âmbito destas pesquisas ainda não há uma vertente teórica especifica para tratar sobre o livro didático.

Os contextos sociais, políticos, econômicos e culturais foram explorados no trabaIho de [34] e [52] e contexto histórico nos trabalhos de [23, 31, 44] e evidenciam uma possibilidade de ampliação do olhar para além do livro didático em sala de aula. A metodologia utilizada nas pesquisas possui, unanimemente, cunho qualitativo e empregou uma abordagem orientada para o produto (análise do livro didático). Não identificamos trabalhos que empregassem o cunho quantitativo e nem que versavam sobre abordagem orientada para o uso do livro didático, seja pelo professor ou pelo aluno e abordagem orientada para o processo (textos que tratavam sobre escrita, desenvolvimento e distribuição de livros didáticos).

Identificamos que, no cenário brasileiro, também é grande o número de pesquisas que analisam o conteúdo ou tema no livro didático. Não identificamos, nos textos analisados, trabalhos que tratem sobre o uso ou como os livros didáticos são produzidos. Tal como aponta [18], entendemos que uma área a ser também explorada é a do livro didático e das tecnologias digitais o que indicamos como possibilidade para pesquisas futuras que produzirão novas peças que poderão ser encaixadas compondo este ou outro(s) mosaico(s) realçando os contornos da pesquisa sobre este recurso didático.

\section{REFERÊNCIAS}

[1] LAJOLO, M. Livro didático: um (quase) manual de usuário. Em aberto (1996) v. 16, n. 69. [Google Scholar] 
[2] BASSO, L. D. P.; TERRAZZAN, E. A. Organização e realização do processo de escolha de livros didáticos em escolas de educação básica. Revista Eletrônica de Educação, v. 9, n. 3 (2015) p. 256-272. [CrossRef] [Google Scholar]

[3] FAN, L. Textbook research as scientific research: towards a common ground on issues and methods of research on mathematics textbooks. ZDM Mathematics Education, v. 45, n. 5 (2013) p. 765-777. [CrossRef]

[4] CHOPPIN, A. História dos livros e das edições didáticas: sobre o estado da arte. Educação e pesquisa, v. 30, n. 3 (2004) p. 549-566. [CrossRef]

[5] AMARAL-SCHIO, R. B. Livro Didático de Ensino Médio, Geometria e a Presença das Tecnologias. RENOTE-Revista Novas Tecnologias na Educação, v. 16, n. 2 (2018) p. 127-137. [CrossRef]

[6] REMILLARD, J. T. Examining teachers' interactions with curriculum resource to uncover pedagogical design capacity. In: FAN, L. et al (ed.) Research on mathematics textbooks and teachers' resources: Advances and Issues. Springer, Cham. (2018) p. 69-88. [CrossRef]

[7] DAVIS, E. A.; KRAJCIK, J. S. Designing educative curriculum materials to promote teacher learning. Educational researcher, v. 34, n. 3 (2005) p. 3-14. [CrossRef]

[8] REMILLARD, J. T. Examining key concepts in research on teachers' use of mathematics curricula. Review of educational research, v. 75, n. 2 (2005) p. 211-246. [CrossRef]

[9] MINAYO, M. C. S. O desafio da pesquisa social. In: MINAYO, Maria Cecília de Souza (org.). Pesquisa social: teoria, método e criatividade. Petrópolis: Vozes (2009) cap. 1, p. 9-29.

[10] CRESWELL, J. W. Projeto de pesquisa: métodos qualitativos, quantitativos e mistos, 3.ed. Porto Alegre: Artmed (2010).

[11] SAMPIERI, R. H.; COLLADO, C. F.; LUCIO, P. B.; Metodologia de pesquisa. 5. ed. Porto Alegre: Penso (2013).

[12] LÜDKE, M.; ANDRÉ, M. E. D. A. Pesquisa em educação: abordagens qualitativas. 2.ed. Rio de Janeiro: E. P. U. (2015).

[13] ALVES-MAZZOTTI, A. J. O método nas ciências sociais. In: ALVES-MAZZOTTI, A. J.; GEWANDSZNAJDER, F. O método nas Ciências Naturais e Sociais: Pesquisa Quantitativa e Qualitativa. São Paulo: Editora Pioneira (1998). p. 107-188.

[14] SOCIEDADE BRASILEIRA DE EDUCAÇÃO MATEMÁTICA REGIONAL PARANÁ. Disponível em: http://www.sbemparana.com.br/viisipem/portuguese/apresentacao.php (2020) (acesso em 15 agosto 2020).

[15] FIORENTINI, D. et al. O professor que ensina matemática como campo de estudo: concepção do projeto de pesquisa. In: FIORENTINI, Dario; PASSOS, Carmen Lúcia Brancaglion; LIMA, Rosana Catarina Rodrigues de.(org.). Mapeamento da pesquisa acadêmica brasileira sobre o professor que ensina matemática: período 2001-2012. Campinas, SP: FE/UNICAMP, (2016). p. 17-41. E-book. Disponível em: https://www.fe.unicamp.br/pf-fe/pagina_basica/ 58/e-book-mapeamento-pesquisa-pem.pdf (2016) (acesso em 01 setembro 2020).

[16] GOMES, R. A Análise de dados em pesquisa qualitativa. In: MINAYO, M. C. S. (org.). Pesquisa social: teoria, método e criatividade. Petrópolis: Vozes, 1 (2013). cap. 4, p. 79-108.

[17] FIORENTINI, D.; LORENZATO, S. Investigações em educação matemática: percursos teóricos e metodológicos. Campinas, SP: Autores Associados (2006).

[18] FAN, L.; ZHU, Y.; MIAO, Z. Textbook research in mathematics education: development status and directions. ZDM Mathematics Education, v. 45, n. 5 (2013) p. 633-646. [CrossRef] 
[19] SILVEIRA, E. Afinal, está certo ou errado? Um estudo sobre indicações de uso de blocos base dez em livros didáticos de matemática no Brasil. In: SEMINÁRIO INTERNACIONAL DE PESQUISA EM EDUCAÇÃO MATEMÁTICA, 7., 2018, Foz do Iguaçu. Anais [...]. Foz do Iguaçu: SBEM/PR (2018) p. 1-12.

[20] QUEIROZ, M. R. P. P. P.; BARBOSA, J. C. Exercícios de livros didáticos de matemática financeira e suas fronteiras com situações do cotidiano e de ambientes de trabalho. In: SEMINÁRIO INTERNACIONAL DE PESQUISA EM EDUCAÇÃO MATEMÁTICA, 6., 2015, Pirenópolis. Anais [...]. Pirenópolis: SBEM/GO (2015) p. 1-12.

[21] LAVE, J.; WENGER, E. Situated learning: legitimate peripheral participation. New York: Cambridge University Press (1991).

[22] SKOVSMOSE, O. Cenários para investigação. Bolema, v. 14, p. 66-91 (2000). [Google Scholar]

[23] SOUZA, J. I.; FLORES, C. R. Uma história da educação financeira na educação básica escolar: uma análise de livros didáticos. In: SEMINÁRIO INTERNACIONAL DE PESQUISA EM EDUCAÇÃO MATEMÁTICA, 7., 2018, Foz do Iguaçu. Anais [...]. Foz do Iguaçú: SBEM/PR (2018) p. 1 12.

[24] FOUCAULT, Michel. A Arqueologia do Saber. 8. ed. Rio de Janeiro: Forense Universitária (2017).

[25] GONÇALVES, Jeferson da Silva Gonçalves; LIMA, Rosana Nogueira. KARRER, Monica. Funções Composta e Inversa e os Registros de Representação Semiótica em Livros Didáticos do PNLD-2015 do Ensino Médio. In: SEMINÁRIO INTERNACIONAL DE PESQUISA EM EDUCAÇÃO MATEMÁTICA, 6., 2015, Pirenópolis. Anais [...]. Pirenópolis: SBEM/GO (2015) p. 1-12.

[26] DUVAL, R. Ver e ensinar a matemática de outra forma: entrar no modo matemático de pensar os registros de representações semióticas. Organização Tânia M.M. Campos. Tradução Marlene Alves Dias. São Paulo: PROEM (2011).

[27] BARROS, R. A.; BOAVENTURA, T. S. L. Uma análise reflexiva sobre a abordagem do conjunto dos números inteiros em livros didáticos do $7^{\circ}$ ano do Ensino Fundamental. In: SEMINÁRIO INTERNACIONAL DE PESQUISA EM EDUCAÇÃO MATEMÁTICA, 7., 2018, Foz do Iguaçu. Anais [...]. Foz do Iguaçú: SBEM/PR (2018) p. 1-12.

[28] GODINO, J. D.; BATANERO, C.; FONT, V. Un Enfoque ontossemiótico del conocimiento y lainstrucción matemática. Berlín, v. 39, n. 1, p. 127-135. Disponível em: http://www.ugr.es/ -jgodino/ funciones-semioticas/sintesis_eos_10marzo08.pdf. (2008) (acesso em 15 agosto 2020).

[29] RIBEIRO, F. L.; PALANCH, W. B. Uma análise da geometria nos materiais curriculares brasileiros pelo enfoque ontossemiótico. In: SEMINÁRIO INTERNACIONAL DE PESQUISA EM EDUCAÇÃO MATEMÁTICA, 7., 2018, Foz do Iguaçu. Anais [...]. Foz do Iguaçú: SBEM/PR (2018) p. 1-12.

[30] SILVEIRA, E. Afinal, está certo ou errado? Um estudo sobre indicações de uso de blocos base dez em livros didáticos de matemática no Brasil. In: SEMINÁRIO INTERNACIONAL DE PESQUISA EM EDUCAÇÃO MATEMÁTICA, 7., 2018, Foz do Iguaçu. Anais [...]. Foz do Iguaçú: SBEM/PR, 2018. p. 1-12.

[31] SILVA, M. A.; SILVA, J. N. D. Movimento modernizador da matemática secundária nos livros didáticos de Stávale e Sangiorgi. In: SEMINÁRIO INTERNACIONAL DE PESQUISA EM EDUCAÇÃO MATEMÁTICA, 5., 2012, Petrópolis. Anais [...]. Petrópolis: SBEM/RJ, (2012) p. 1-19.

[32] GUIMARÃES, G. O uso de recursos didáticos na aprendizagem do sistema de numeração decimal: análise das atividades propostas em livros didáticos brasileiros e espanhóis. In: SEMINÁRIO INTERNACIONAL DE PESQUISA EM EDUCAÇÃO MATEMÁTICA, 5., 2012, Petrópolis. Anais [...]. Petrópolis: SBEM/RJ (2012) p. 1-19.

[33] BARBOSA, E. J. T.; LINS, A. F. Organização Praxeológica: equação do primeiro grau em livros didáticos do $7^{\circ}$ ano do Ensino Fundamental. In: SEMINÁRIO INTERNACIONAL DE PESQUISA EM EDUCAÇÃO MATEMÁTICA, 5., 2012, Petrópolis. Anais [...]. Petrópolis: SBEM/RJ, 2012. p. 1-19. 
[34] VALERO, Paola et al. O cidadão matematicamente competente no currículo e nos livros didáticos brasileiros e suecos. In: SEMINÁRIO INTERNACIONAL DE PESQUISA EM EDUCAÇÃO MATEMÁTICA, 7., 2018, Foz do Iguaçu. Anais [...]. Foz do Iguaçu: SBEM/PR (2018) p. 1-12.

[35] PRADO, Airam da Silva; OLIVEIRA, Andréia Maria Pereira. O discurso regulativo nos materiais curriculares educativos sobre modelagem matemática. In: SEMINÁRIO INTERNACIONAL DE PESQUISA EM EDUCAÇÃO MATEMÁTICA, 5,2012, Petrópolis. Anais [...]. Petrópolis: SBEM/PR (2012) p. 1-22.

[36] BALL, D. L.; COHEN, D. K. Reform by the book: what is - or might be - the role of curriculum materials in teacher learning and instructional reform? Educational Researcher, v. 25, n. 9, p. 6-14, 1996. [CrossRef]

[37] BERNSTEIN, B. Class, Codes and Control, volume IV: the structuring of pedagogic discourse. London: Routledge (1990).

[38] PACHECO, D. R.; Pires, C. M. C. Espaço e Forma nos Anos Iniciais e o uso de Materiais Curriculares. In: SEMINÁRIO INTERNACIONAL DE PESQUISA EM EDUCAÇÃO MATEMÁTICA, 6. 2015, Pirenópolis. Anais [...]. Pirenópolis: SBEM/GO, (2015) p. 1-12.

[39] BROWN, M. W. The Theacher-Tool Relationship: Theorizing the Desing and Use of Curriculum Materials. In: REMILLARD, J. T.; Herbel-Eisenmann, B. A.; Lloyd, G. M. (ed.). Mathematics teachers at work: Connecting curriculum materials and classroom instruction (Studies in Mathematical Thinking and Learning Series, A. Schoenfeld, Ed.). New York: Routledge (2009).

[40] LIMA, Kátia. Quadro Analítico para a Avaliação de Materiais Curriculares por Professores de Matemática. In: SEMINÁRIO INTERNACIONAL DE PESQUISA EM EDUCAÇÃO MATEMÁTICA, 6. , 2015, Pirenópolis. Anais [...]. Pirenópolis: SBEM/GO (2015) p. 1-12.

[41] DAVIS, E. A.; KRAJCIK, J. S. Designing educative curriculum materials to promote teacher learning. Educational researcher, v. 34, n. 3, p. 3-14, 2005. [CrossRef]

[42] STEIN, Mary Kay; KIM, Gooyeon. The Role of Mathematics Curriculum Materials in Large-Scale Urban Reform: An Analysis of Demands and Opportunities for Teacher Learning. In: REMILLARD, J. T; HERBEL-EISENMANN, B. A.; LLOYD, G. M. (ed.), Mathematics Teachers at Work: Connecting curriculum materials and classroom instruction. New York: Taylor \& Francis (2009) p. 37-55.

[43] FONSECA, Carla Isabel Teixeira Tavares Rebimbas da. As funções exponencial e logarítmica nos manuais escolares do $12^{\circ}$ ano (2013) 165f. Dissertação (Mestrado em Didática) - Departamento de Educação, Universidade de Aveiro. Portugal.

[44] LIMA, K.; JANUARIO, G.; MANRIQUE, A. L. A aprendizagem do professor mediada por sua relação com materiais curriculares de matemática. In: SEMINÁRIO INTERNACIONAL DE PESQUISA EM EDUCAÇÃO MATEMÁTICA, 7., 2018, Foz do Iguaçu. Anais [...]. Foz do Iguaçu: SBEM/PR (2018) p. 1-12.

[45] MARQUES, J. A. O. Manuais portugueses e a escola nova: o ensino de matemática no curso primário brasileiro. In: SEMINÁRIO INTERNACIONAL DE PESQUISA EM EDUCAÇÃO MATEMÁTICA, 5., 2012, Petrópolis. Anais [...]. Petrópolis: SBEM/RJ (2012) p. 1-17.

[46] FREITAS, I. C.; ORTIGÃO, M. I. R. O PNLD está chegando: e agora, como escolher o livro didático de matemática? In: SEMINÁRIO INTERNACIONAL DE PESQUISA EM EDUCAÇÃO MATEMÁTICA, 5., 2012, Petrópolis. Anais [...]. Petrópolis: SBEM/RJ (2012) p. 1-20.

[47] CURI, E. Orientações Curriculares, Livros Didáticos, Prova Brasil de Matemática do $5^{\circ}$ ano e Práticas de Sala de Aula: Resultados de uma Pesquisa Longitudinal. In: SEMINÁRIO INTERNACIONAL DE PESQUISA EM EDUCAÇÃO MATEMÁTICA, 6., 2015, Pirenópolis. Anais [...]. Pirenópolis: SBEM/GO (2015) p. 1-13.

[48] SACRISTÁN, J. G. O currículo: uma reflexão sobre a prática. Porto Alegre: ArtMed, (2000). [Google Scholar] 
[49] RICO R. L. El método del Análisis Didáctico. Unión - Revista Iberoamericana de Educação Matemática. Madrid, v. 9, n. 33, p. 11-27, (2013). [Google Scholar]

[50] JANUARIO, G.; PIRES, C. M. C. Análise de Questões em Pesquisas sobre Livros Didáticos de Matemática. In: SEMINÁRIO INTERNACIONAL DE PESQUISA EM EDUCAÇÃO MATEMÁTICA, 6., 2015, Pirenópolis. Anais [...]. Pirenópolis: SBEM/GO (2015) p. 1-12.

[51] POSTLETHWAITE, T. Neville. Educational research: some basic concepts and terminology. Paris: UNESCO International Institute for Educational Planning, 2005.

[52] NETO, V. Livros didáticos de matemática para o campo: aqui também se aprende a ser mãe. In: SEMINÁRIO INTERNACIONAL DE PESQUISA EM EDUCAÇÃO MATEMÁTICA, 7., 2018, Foz do Iguaçu. Anais [...]. Foz do Iguaçú: SBEM/PR, 2018. p. 1-12.

[53] BECKER. Howard, S. Métodos de pesquisa em ciências sociais. Tradução: Marco Estevão, Renato Aguiar, Revisão técnica: Márcia Arieira, 4ª Ed, São Paulo: Hucitec, (1999).

\section{BREVE BIOGRAFIA}

Ana Paula Perovano (D) https://orcid.org/0000-0002-0893-8082

Doutoranda em Educação Matemática (UNESP). Mestre em Educação Matemática (PUC-SP). Professora da Universidade Estadual do Sudoeste da Bahia (UESB). Integrante do Grupo de Pesquisa TeorEMa - Interlocuções entre Geometria e Educação Matemática. Desenvolve estudos e pesquisas sobre Formação de Professores, Livros Didáticos de Matemática e Processos de Ensino e de Aprendizagem da Matemática.

Douglas Ribeiro Guimarães (D) https://orcid.org/0000-0001-6247-3506

Mestrando em Educação Matemática (UNESP/Rio Claro) e Licenciado em Matemática (UNESP/Rio Claro). Integrante do Grupo de Pesquisa TeorEMa - Interlocuções entre Geometria e Educação Matemática e do Grupo de Pesquisa em Informática, outras Mídias e Educação Matemática (GPIMEM). Desenvolve pesquisas sobre Livros Didáticos de Matemática e estudos em Educação Matemática Crítica. 